\title{
Residential energy monitoring: a case study of four sub metered homes
}

\author{
M. Hatch \& H. Rashed-Ali \\ Department of Architecture, The University of Texas at San Antonio, USA
}

\begin{abstract}
This paper outlines results obtained from an energy analysis of four sub metered residences. The study was done through a partnership between the Department of Architecture at the University of Texas at San Antonio and a design firm interested in learning from the data collected to influence design decisions. The study allowed for a performance evaluation of existing case studies and for the firm to improve upon design assumptions and modeled predictions for future designs.

No prescriptive guidelines exist by which to measure and analyze sub metered residential data. A monitoring and analysis protocol was developed and applied in order to address this issue. Each home was monitored at the breaker level to allow for the measurement of residential end uses. The homes were analyzed individually and then comparatively.

Results and conclusions centered on the performance and schedule of geothermal heating and cooling systems, pools, water heaters, and lighting. The analysis provided concise diagnostics and suggestions for each home as well as a unique conclusion for the future of residential design. When studied comparatively, the data from these homes suggests that residences with the ability to grow and shrink electrical consumption based on demand use less energy overall. This may suggest that designing a home with the ability to adapt electrical demand based on need may result in less total consumption.

Keywords: sustainable design, residential, sub metering, energy monitoring, energy efficiency, post occupancy evaluation.
\end{abstract}

\section{Introduction}

This case study presents the results of four sub metered homes monitored for electrical consumption by a design firm and analyzed in partnership with the 
Department of Architecture at the University of Texas at San Antonio. The broad objective of the case study was to identify how the homes were using energy in order to understand if the design process was focused on reducing energy use in the right areas.

\subsection{Goal and scope of project}

The ability to accurately predict the energy use of a final project is a current challenge faced by design teams. During design development, the firm incorporated residential information in combination with energy modeling software to inform design decisions including lighting choices, construction techniques, orientation, etc. Once the projects were built and occupied, the firm used the opportunity to verify and improve upon the accuracy of predictions and modeled assumptions. The firm is then able to adapt areas of focus to reduce energy consumption in the case studies and for future projects.

\subsection{The residences}

Of the four homes studied, three of the homes were designed by the firm while the fourth home was the residence an employee used to provide comparison. Three homes included specialized equipment, such as geothermal systems and pools, with the fourth home using a conventional air-to-air HVAC system. The homes ranged in size from 800 to 7,000 square feet and in occupancy patterns from fulltime to weekend houses. Three homes are located in central Texas, while the fourth is located in East Hampton, New York.

Table 1: Residential case studies.

\begin{tabular}{|c|c|c|c|c|}
\hline & Case Study A & Case Study B & Case Study C & Case Study D \\
\hline Location & Central TX & $\begin{array}{l}\text { East Hampton, } \\
\text { NY }\end{array}$ & Central TX & Central TX \\
\hline \# of occupants & 2 & 4 & 2 & 1 \\
\hline Occupancy & Part-time & Weekends & Year-round & Year-round \\
\hline Size $\left(\mathrm{ft}^{2}\right)$ & 2,836 & 7,187 & 2,100 & 850 \\
\hline \# of floors & 2 & 1 (+basement) & 1 & 1 \\
\hline HVAC & $\begin{array}{l}\text { Geothermal } \\
\text { pond coil }\end{array}$ & $\begin{array}{l}\text { Geothermal } \\
\text { forced air and } \\
\text { radiant heating } \\
\text { with gas boiler }\end{array}$ & Geothermal & Air-to-air \\
\hline DHW system & Geothermal & $\begin{array}{l}\text { Geothermal and } \\
\text { gas }\end{array}$ & Geothermal & Electric \\
\hline Unique system & Pool & Pool & Pool & None \\
\hline PV system & No & No & No & No \\
\hline
\end{tabular}

\subsection{Methodology}

\subsubsection{Measurement}

The homes were monitored for whole house electric totals along with usage at the level of individual breakers. Monitoring began at varying months in 2014 using SiteSage Gateway and Energy Monitor system. The systems were installed by a 
certified electrician with individual circuit labels recorded for categorizing end uses. Data was recorded at hourly and daily intervals.

Basic information for each home, including a description of size, location, and major systems, was recorded. The exterior temperature was recorded for all homes, with an additional measurement of interior temperature for Case Study A. Data for this case study was initially pulled on June 11th, 2015. After initial analysis, time was allotted to allow for a larger data set. The final data set was pulled October 7th, 2015.

\subsubsection{Analysis}

Analysis procedures were created utilizing existing protocols and similar case studies. The analysis was performed on raw data gathered from the monitoring system to provide a deeper understanding of performance past the initial analysis provided by SiteSage.

Accuracy was determined by measuring the difference between the summed circuit loads and the main meter. Data containing errors greater than $20 \%$ was discarded. A total time span of collection was recorded and outages were noted. As a full year of data was not available when accounting for outages and accuracy errors, complete months were noted for individual analysis.

Circuits were grouped and summed into two levels of consumption for comparison to RECS 2009 [1]. End use categories were pulled from RECS benchmarks as Space Heating, Air Conditioning, Water Heating, and Appliances, Electronics, and Lighting, along with the addition of a Pool category. Detailed end use categories were developed specific to the residence. For example, some circuit panels enabled the split into individual categories for specific measurement of Appliances, Electronics, or Lighting.

Each home was compared to RECS 2009, analyzed for total monthly consumption, average hourly performance per month, peak days in the summer and winter seasons, and concluded with specific diagnostics and recommendations. Additionally, the four residences were compared and analyzed by monthly electrical use per person, monthly electrical use per square foot, and the monthly load factor to observe overall trends.

\section{Affirmed design strategies}

Affirmed design strategies represent successful examples of design through strongly correlated data. Successful results were grouped to summarize beneficial strategies within the four case studies and include effective daylighting, programmable thermostats, and user satisfaction through peak usage of appliances and plug loads during holidays.

\subsection{Effective daylighting}

Strong evidence of effective daylighting was found for Case Studies A and B with minimal electric lighting during the day and monthly usage declining during the longer days of summer (Figures 1 and 2). 


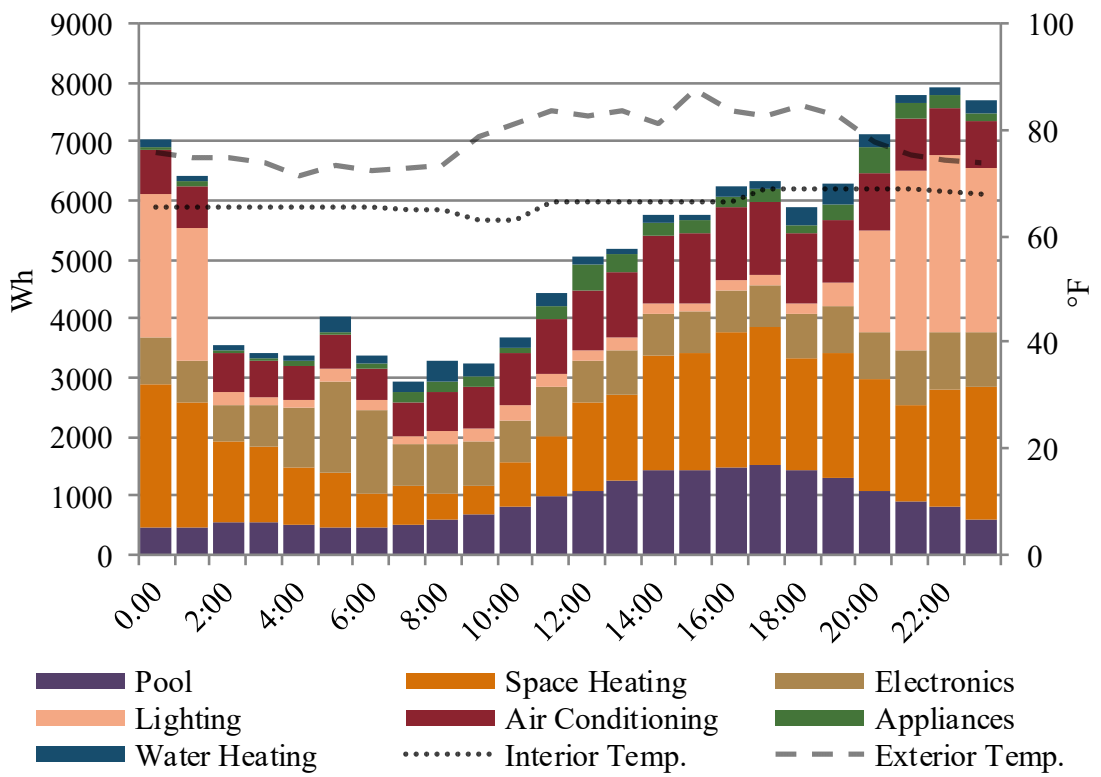

Figure 1: Hourly averages from June 2015 for Case Study A.

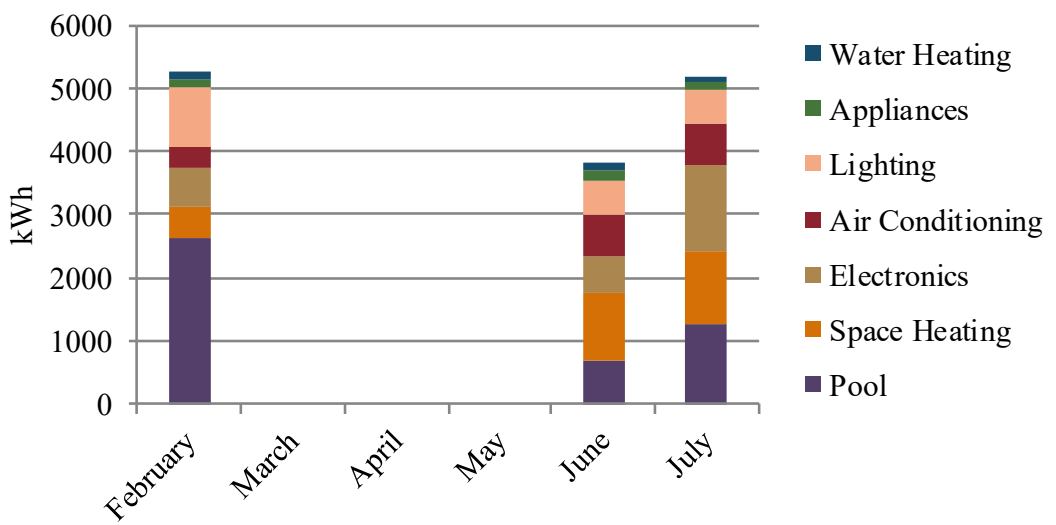

Figure 2: Monthly end uses of Case Study A.

\subsection{Programed thermostat}

Case Study D exhibited the benefits of a successfully calibrated programmable thermostat. The HVAC use generally peaked in the evening and morning, yet fell significantly during the day for every month except August and September 2015 (Figure 3). This suggests a programmable thermostat set to cool and heat the home only when occupied. 


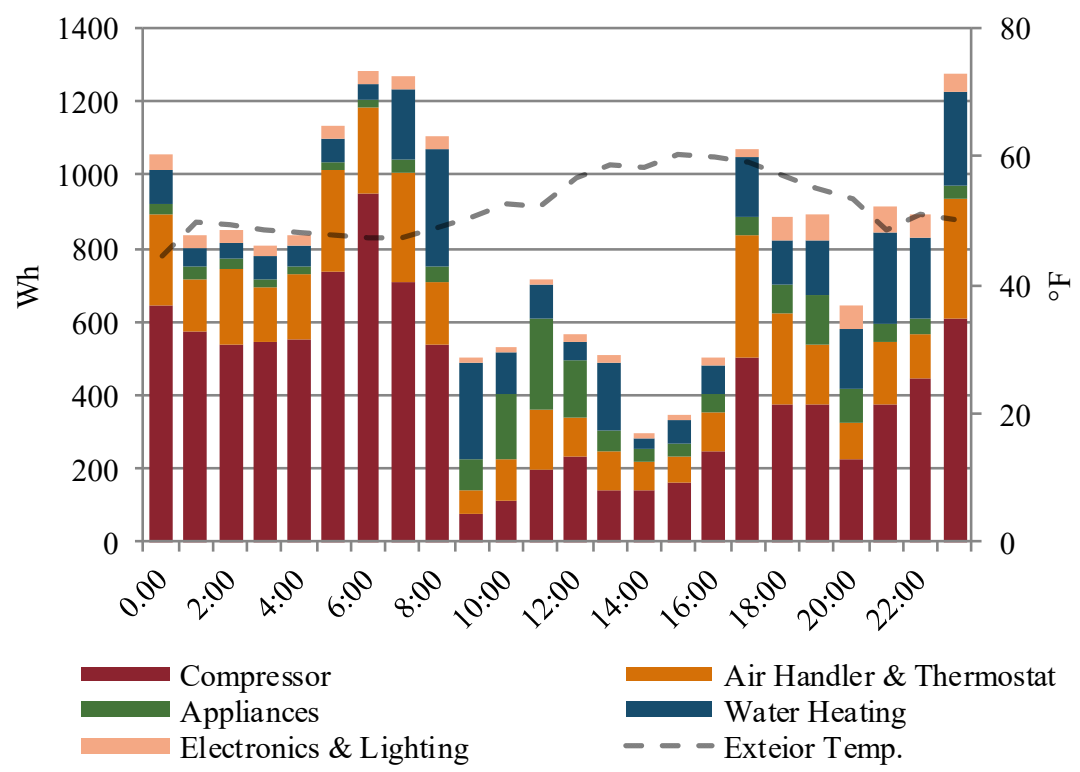

Figure 3: Hourly averages of February 2015 for Case Study D.

\subsection{User satisfaction}

The peak winter and summer days for Case Study $\mathrm{C}$ outlined social activities with a notable increase in appliances, electronics, and lighting. Both the peak winter and summer days were likely the result of social gatherings, including a summer party and hosting Christmas (Figure 4). Such indications can be taken as a representation of the customer satisfaction and pride in the home.

\section{Diagnostics and recommendations}

Diagnostics and recommendations for the four case studies were grouped by theme and centered around the design and specification of systems involved in thermal comfort, hot water heating, pools, and electric lighting. Overall improvements centered around equipment creating temperature change and/or pumps moving liquid for geothermal or pool systems.

\subsection{Security lighting}

Electric lighting in Case Study A was significant between the hours of 9pm and 2am (Figure 1). This suggests the lights were on a timer to increase security at night. It is recommended to provide more efficient lighting or an alternative lighting design for safety lighting at night. 


\subsection{Geothermal and air-to-air HVAC systems}

\subsubsection{Additional measurement}

Case Studies A and C are both noted to have geothermal equipment with a geothermal pond coil and a geothermal HVAC, however, a geothermal pump or other related equipment is not recorded (Table 1). All specialized equipment should be noted in the sub meter installation. Specific components of larger systems should be separately marked and recorded. This allows direct diagnostics for the systems representing greater investments (U.S. EIA [2]).

Recording interior thermal conditions, in addition to exterior, is recommended to allow for the comprehensive analysis of HVAC systems, as seen in Case Study A (Figure 1). Interior temperature analysis would enable more definitive recommendations for thermal efficiency while accounting for the personal preferences of occupants.

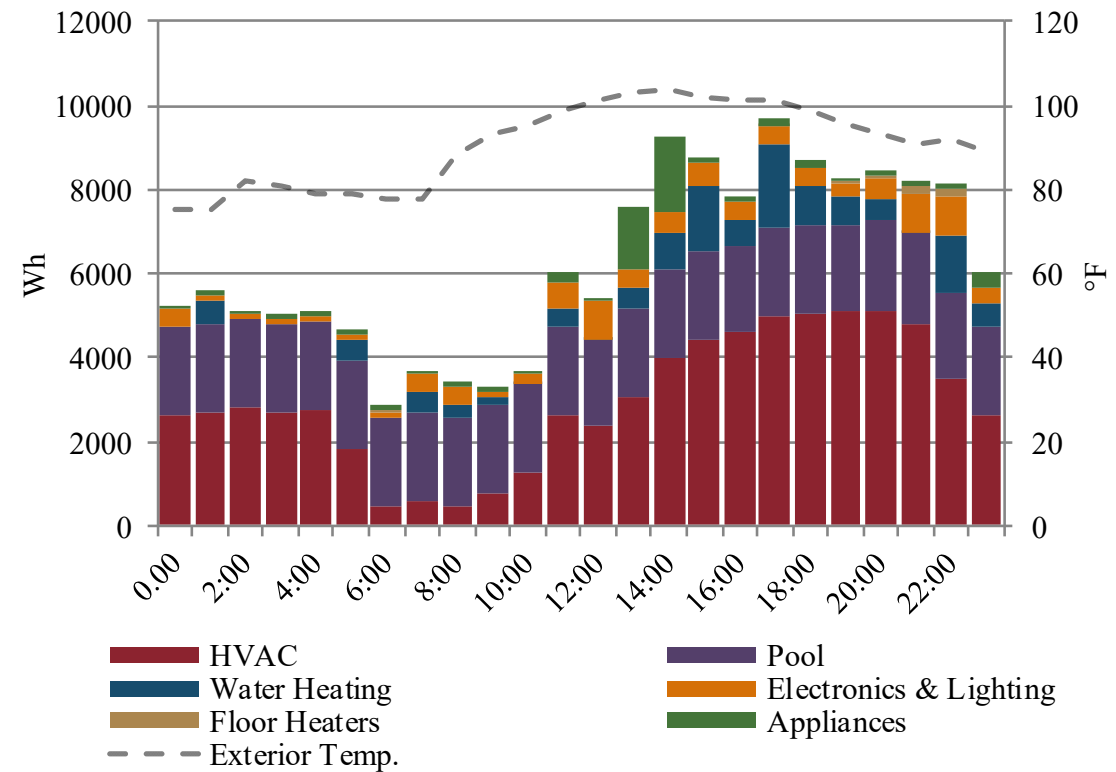

Figure 4: Peak winter day on December 25th, 2014 for Case Study C.

\subsubsection{Geothermal well pump}

Case Study B provides an example of the performance characteristics of a sub metered geothermal system. The geothermal unit and boiler consumed more in the winter, while the air handler consumed more during the summer months. The well pump accounted for a large amount the total consumption, at nearly half of the whole building consumption in the heating and cooling months (Figure 5). 


\subsubsection{Boiler programming}

The amount of space heating for Case Study A was found to be significant for June and July (Figures 1 and 2). The constant interior temperature may indicate simultaneous heating and cooling. As space heating increased in the summer months, it is likely that the HVAC system requires troubleshooting. This could result in possible cost savings by simply reprogramming the system.

\subsubsection{Air-to-air HVAC recommendations}

As a smaller home in a hot and humid climate, the compressor in Case Study D is the dominating load for the majority of the year. The air handler and thermostat are the next largest consumer, both peaking in accordance to exterior temperatures (Figure 3). If any home improvements are to occur, focusing on compressor efficiency and the building envelope are likely to produce the most cost effective results (Sherwin et al. [3]).

\subsubsection{System comparison to RECS 2009}

A measurement of system performance was provided by combining HVAC and hot water heating for comparison against RECS 2009 (Table 2). However, the efficiency of the geothermal and air-to-air HVAC systems cannot be directly compared, given the additional provision of hot water from the geothermal systems and the varying climactic zones and occupancy schedules. Averages are approximate and represent varying lengths of time from three to twelve months, and may not represent full seasonal variation.

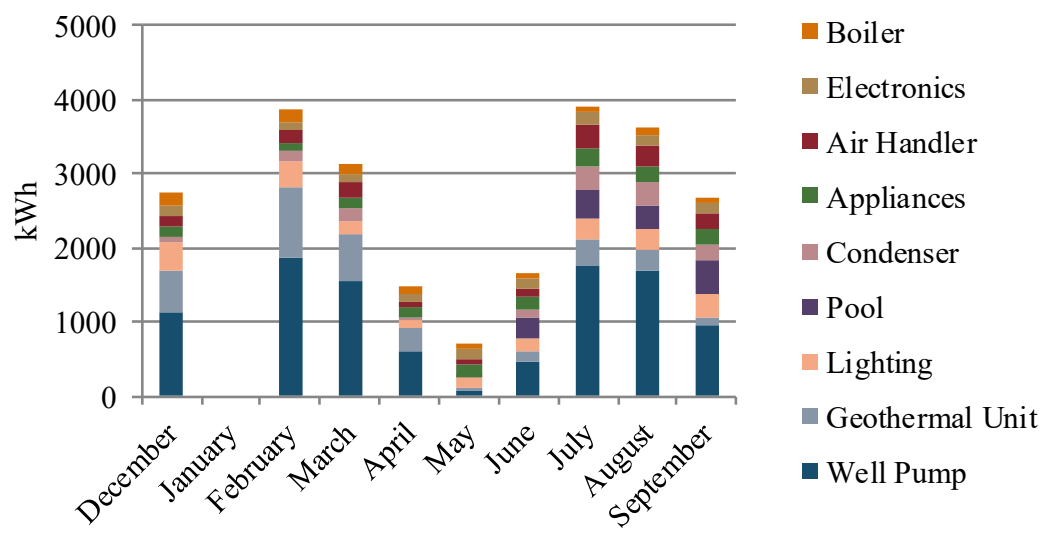

Figure 5: Monthly end uses of Case Study B.

Table 2: Space heating, air conditioning, and water heating consumption (RECS Texas [1] and RECS New York [4]).

\begin{tabular}{|c|c|c|c|c|}
\hline & Case Study A & Case Study B & Case Study C & Case Study D \\
\hline RECS 2009 & $59 \%(\mathrm{TX})$ & $74 \%(\mathrm{NY})$ & $59 \%(\mathrm{TX})$ & $59 \%(\mathrm{TX})$ \\
\hline Case study average & $50 \%$ & $73 \%$ & $81 \%$ & $77 \%$ \\
\hline Systems & $\begin{array}{l}\text { Geothermal } \\
\text { pond coil }\end{array}$ & $\begin{array}{l}\text { Geothermal and } \\
\text { radiant heating } \\
\text { with gas boiler }\end{array}$ & $\begin{array}{l}\text { Geothermal } \\
\text { system }\end{array}$ & $\begin{array}{l}\text { Air-to-air with } \\
\text { electric tank } \\
\text { water heater }\end{array}$ \\
\hline
\end{tabular}


Despite dominating percentages of well pump power (Figure 5), the average percentage of HVAC and water heating from geothermal systems in Case Studies A and B compare well with the estimated percentages of RECS 2009. The extreme percentage of Case Study $C$ is attributed to the erroneous configuration of the space heating system (3.2.3). The dominating percentage of HVAC load in Case Study D is attributed to the reduced size of the home, at 850 square feet, compared to the Texas average of 1,757 square feet (Residential Energy Consumption Survey Texas [1]). Although comparable, further research is recommended to include larger datasets encompassing the full spectrum of seasonal variation with directly comparable traditional systems.

\subsection{Tank water heaters}

Case Study D was the only residence with an electric tank water heater. From analysis, water heating was found to be significantly higher during the cooler months of November, December, and February, pulling a larger than average load every several hours (Figure 3). The frequency of hot water in the winter months suggests loss of heat within the storage tank. After discussion with the owner, it was found that the tank is located outside and is uninsulated. Insulating the water heater may result in the greatest cost savings for the overall cost of improvement.

\subsection{Floor heaters}

Case Study $\mathrm{C}$ featured two floor heaters, one of which was used from January through the end of the dataset in May (Figure 7). The floor heater ran from 4:00am to $9: 00 \mathrm{am}$, then again from $3: 00 \mathrm{pm}$ to $10: 00 \mathrm{pm}$, often in conjunction with increased HVAC (Figure 6). The floor heater may have been set to a timer and forgotten or it may be a personal preference to run the heater during an evening shower, as the heater often runs in conjunction with water heating in the evening. A diagnostic of the HVAC system and of any timers associated with the floor heaters is recommended to ensure comfort while reducing loads.

\subsection{Pools}

\subsubsection{Pool pumps}

A significant drop in pool usage for Case Study C can be noted after October 2015 (Figure 7). This suggests systems associated with the pool were previously recognized as erroneous and adjusted accordingly. The pool pump ran continuously through October then dropped to run only between 7:00am and 2:00pm in November. This schedule has remained constant suggesting satisfaction with the cleaning performance of the pump schedule (Figure 6).

\subsubsection{Pool heaters}

The two pool furnaces in Case Study A added the most significant contribution to electrical consumption in the colder temperatures of February (Figure 2). In June and July, the pool shows a reduction in consumption, with just the pump running selectively during the afternoon and into the evening (Figures 1 and 2). Post 
analysis indicated that the occupant was training for a competition. A timer is recommended to heat the pool during specified hours, excluding hours unlikely to be used for training. Residences with pool furnaces may benefit from up front efficiency considerations.

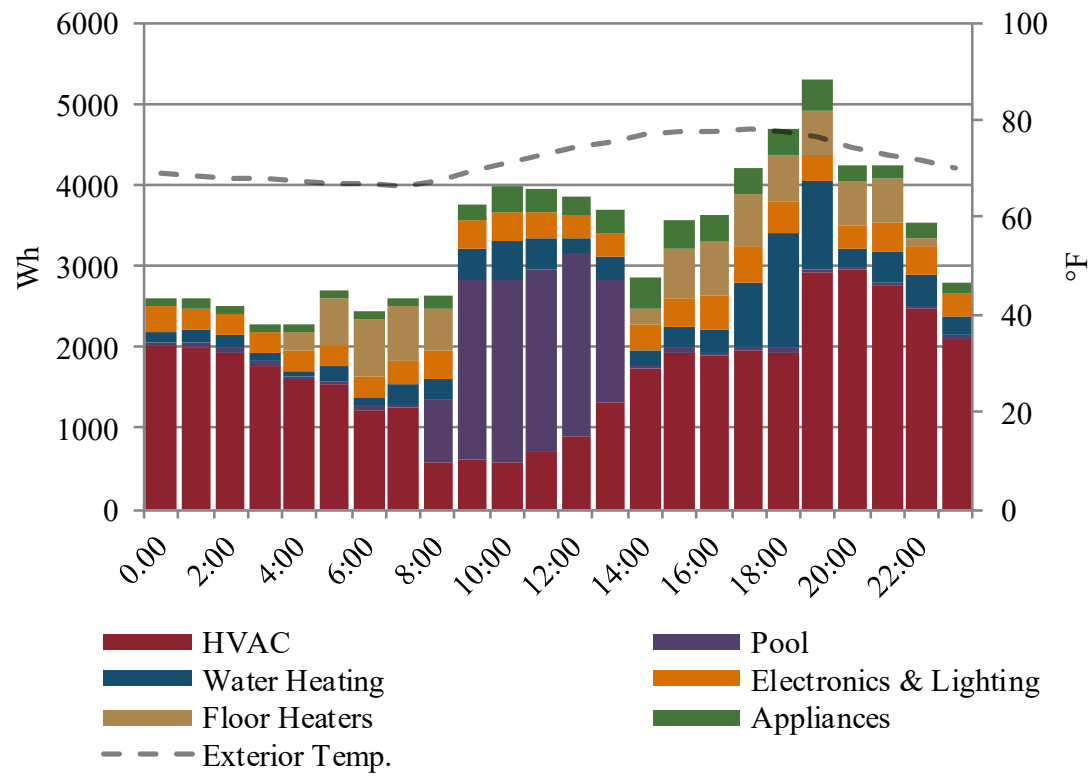

Figure 6: Hourly averages in May 2015 for Case Study C.

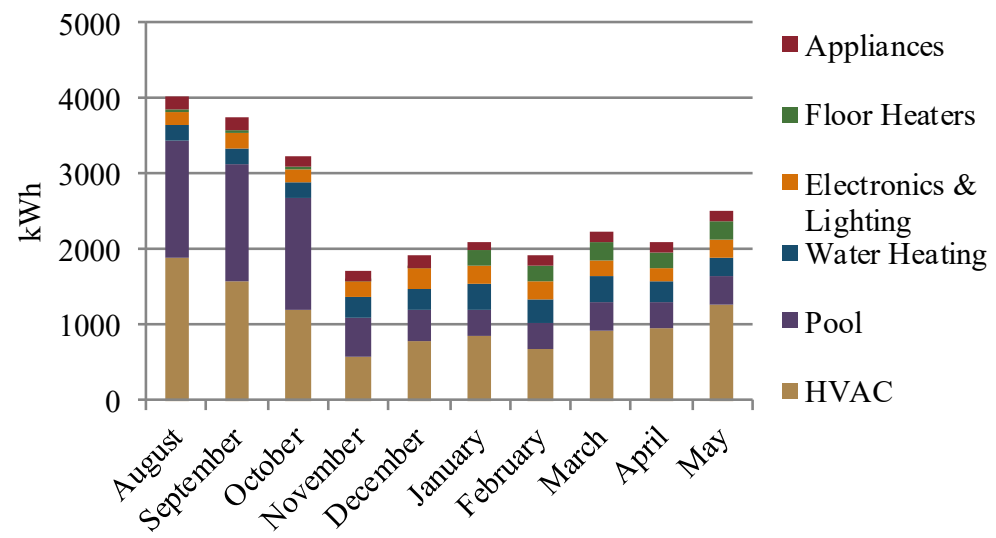

Figure 7: $\quad$ Monthly end uses for Case Study C. 


\section{Home comparison}

Three metrics were used to provide comparison between the four residences. Standard intensity per square foot was calculated as $\mathrm{kWh}$ per square foot per month. The intensity per person was calculated as $\mathrm{kWh}$ per person per month, accounting for variations in occupancy. Finally, the load factor for each month was calculated by comparing the peak daily load recorded to the average total daily consumption. This enables an understanding of the variation and scale of fluctuation of the demand of a home.

When comparing monthly electricity use per person to the monthly use per square foot, nearly the same picture of scale emerges. In both metrics, Case Study $\mathrm{C}$ is by far the largest consumer, with Case Study D recording the second to smallest intensity, and Case Study B recording the lowest (Figures 8 and 9). When measured per person, Case Study A is notably lower in intensity than Case Study C. However, when examined per square foot, Case Study A is greater in intensity during the summer months. This difference, along with the lowest intensity measurement of Case Study B, is most likely attributed to larger homes with parttime occupancies.

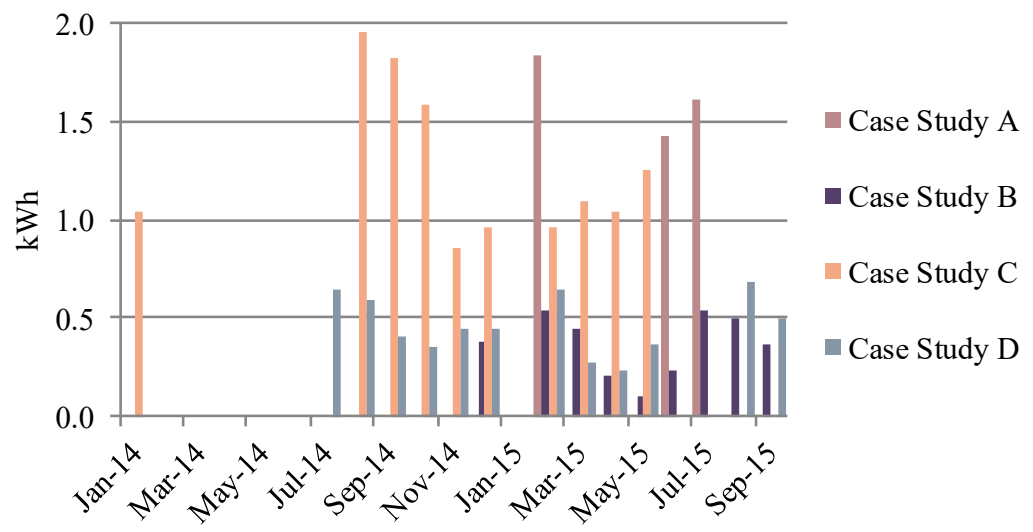

Figure 8: Electricity per square foot.

Traditionally, a smaller load factor would be considered an indicator of "right sizing' the design. However, this study found that the greatest intensity users consistently had the smallest load factors (Figure 10). The less intensive properties, Case Study B and Case Study D, have the greatest load factor accounting for the variations in consumption seen within the home. This may suggest that designing a home with the ability to expand and shrink electricity consumption as needed may result in less total consumption. 


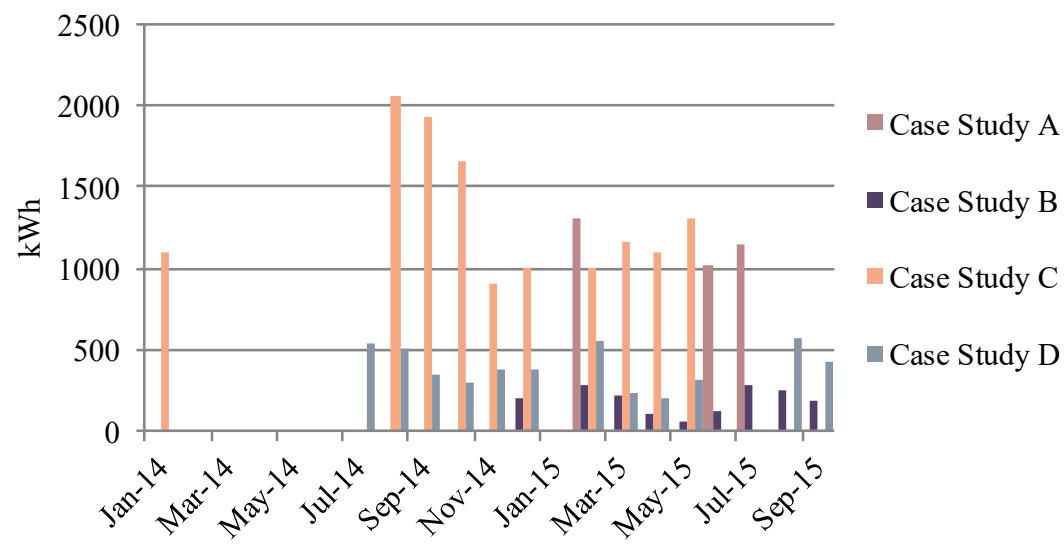

Figure 9: Electricity per person.

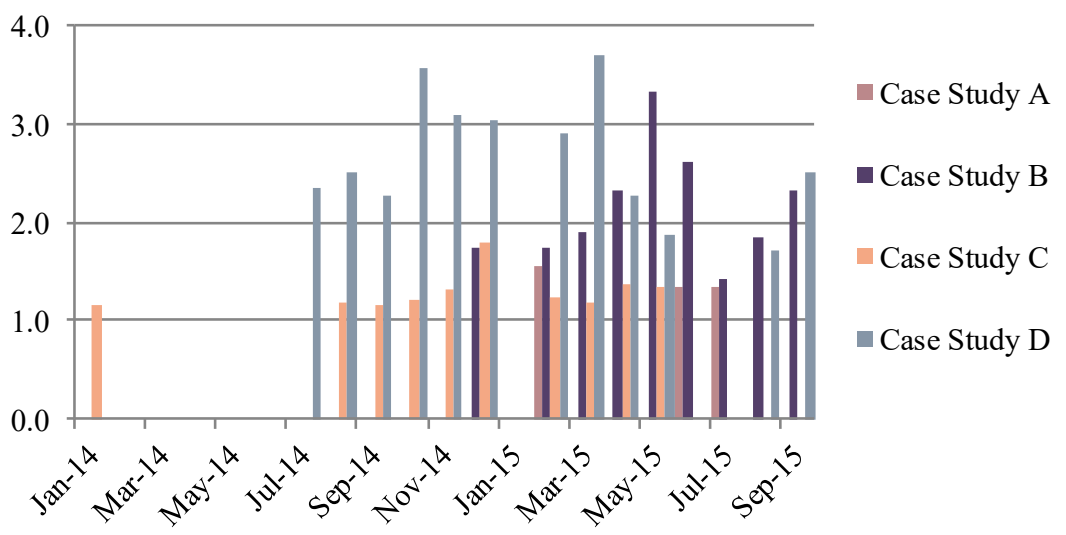

Figure 10: Load factor for case study comparison.

\section{Summary, conclusions, and future work}

This case study began with the task of drawing concise conclusions from datasets representing four sub metered residences. Analysis procedures were developed based on existing methodologies and case studies.

Successful results included effective daylighting, programmable thermostats, and user satisfaction through peak usage of appliances and plug loads during holidays. Diagnostics and recommendations centered around equipment used for changing temperature for thermal comfort and hot water, security lighting, and pumps used for geothermal systems or pools. When studied comparatively, the data from these homes suggests that designing a home with the ability to adapt its energy use as needed may result in less total consumption. 
This case study is able to provide feedback to the design firm of the projects, provide a model for the scope of analysis for residential sub metering, as well as share specific conclusions observed from built and occupied residences. Ideally, these concepts will be implemented and explored further by architectural design firms to provide a closed-loop learning opportunity to create design solutions that meet the needs of the occupants.

\section{References}

[1] Residential Energy Consumption Survey, Household Energy Use in Texas: A closer look at residential energy consumption. U.S. Energy Information Administration, 2009.

[2] U.S. Energy Information Administration, An Assessment of Interval Data and their Potential Application to Residential Electricity End-Use Modeling. U.S. Department of Energy, 2015.

[3] Sherwin, J., Colon, C., Parker, D., \& Martin, E., Performance of Four Near Zero Energy Homes: Lessons Learned, Florida Solar Energy Center, 2010.

[4] Residential Energy Consumption Survey, Household Energy Use in New York: A closer look at residential energy consumption. U.S. Energy Information Administration, 2009. 